\title{
Optimal Placement of Distribution Generation Sources in Hybrid Generation Network
}

\author{
Danish Ali, Ward Ul Hijaz Paul*, Md Safdar Ali, Mubassir Ahmad, Haroon Ashfaq \\ Department of Electrical Engineering, Jamia Millia Islamia, New Delhi, India \\ Email: *wardulhijazpaul@gmail.com
}

How to cite this paper: Ali, D., Paul, W.U.H., Ali, M.S., Ahmad, M. and Ashfaq, H. (2021) Optimal Placement of Distribution Generation Sources in Hybrid Generation Network. Smart Grid and Renewable Energy, 12, 65-80.

https://doi.org/10.4236/sgre.2021.125005

Received: April 19, 2021

Accepted: May 28, 2021

Published: May 31, 2021

Copyright ( 2021 by author(s) and Scientific Research Publishing Inc. This work is licensed under the Creative Commons Attribution International License (CC BY 4.0).

http://creativecommons.org/licenses/by/4.0/

(c) (i) Open Access

\begin{abstract}
The ideal places and size of the distribution generators were determined by reducing the loss of power in the distribution networks. The ideal positioning of various kinds of DGs has been suggested in the current job. In this job, the ideal power factor for DG supply has been acquired, both the active power as well as the reactive power. In the proposed approach, different types of distribution generation (DG) supply both reactive and real power. For the optimal placement of DG sources, particle swarm optimization techniques have been used in this job. Each of these innovations has its own strengths and drawbacks. Most of the methods that have been proposed so far to formulate DG's optimum placement problem only consider Type-I DGs, Type-II and Type-III DGs that are considered for optimal position in the existing research. In the reference, artificial bee colony algorithm was used to determine sites of DGs and condenser combinations and optimal size. The author used PSO method in the reference to determine the appropriate positioning of the DG's and to maximize the savings of power loss and voltage profile in the distribution network.
\end{abstract}

\section{Keywords}

Distribution Generators, Renewable Integration, Optimal Allocation, Particle Swarm Optimization

\section{Introduction}

The power system is a network that consists of a system of generation, distribution, and transmission. Electricity is generating by converting mechanical energy to electrical energy. The transmission line carries the energy to the different substations. The power gets transferred to the distribution transformer through the substation, which step-downs the electricity to the correct market level. 
The generating substation's power plant is mainly divided into three groups, i.e., thermal power plant, hydroelectric power plant and nuclear power plant. The generator and the transformer are the station's main components.

The portion of an electrical power system that connects all customers in a region to the bulk power sources is called a distribution system. Transmission lines link the bulk power stations to the generating substations. We feed other substations that are usually located near the load centers at convenient points. The substations transmit the energy to customers at home, in industry and relatively small. Customers require large power blocks that are normally delivered on a sub-transmission or even transmission system.

Power systems analysis is a huge and significant portion of electrical engineering studies. It is primarily concerned with the generation and distribution of electrical power from the sending end to the receiving end as per customer requirements resulting in a minimum number of losses. The power at the end of the user frequently varies as a result of load fluctuations or disruptions within the transmission line width. The term Power System Stability is therefore of paramount importance in this field. It is used to describe the system's ability to restore its activity to a stable state condition within a reasonable period of time after any transience or disruption in the line has been encountered. In modern society, the electrical grid is important. Without it, it would struggle and break down a lot of society. Hence, ensuring the reliability of the electrical grid in all circumstances is important. We research reliability of power systems to learn how to prevent power outages and blackouts and to increase reliability of the network. There's so much life running on electricity. Nearly every facet of modern life depends on electricity, from storing food, to communicating with family, to carrying out financial transactions. It is a basic and central pillar of society as a whole. Imagine what would happen if for a day, then a week, then a month or longer you lost power. It was going to be chaos. It is therefore important to research the efficiency of the power system. There are several entities that concentrate on efficiency of the power system from an administrative point of view (use and network operators) to a regulatory point of view (state public utility commissions and NERC). Everyone, like we do at ERCOT, needs to study, and make their company efficient in order to ensure that the grid is stable and gives society energy.

This paper is presented as follows. The introduction, structure of power system i.e., generation, transmission \& distribution and the reliability is discussed in the chapter 1 . In chapter 2 , the literature review is discussed along with all the four type of DGs and the detailed discussion about the embedded generation. The power loss minimization is discussed in the chapter 3. The two techniques employed to obtain the optimal results are also discussed in the chapter 3 . The system modeling is discussed for various types of DG systems in the chapter 4 . The simulation results are discussed for the various types of DGs in the chapter 5. Chapter 6 includes the conclusion. 


\section{Literature Survey}

Reliable and economical power system network is to provide all the necessities at all the sites in the power system network. In the earlier days for the generation of electricity ordinary energy resources were used such as hydro, nuclear, and fossil fuels. The operation of conventional generation system is based on centralized control generator. Transmission and distribution network is used to deliver the power in the network. Nowadays, centralized plants system is weakening because of the increased in distribution and transmission cost, environment concern, depleting traditional resources and advancement in the technologies. Distributed Generations (DGs) offer solution to several new conflicts and generally used for small scale generation.

DGs are also called as "Disperse Generations" or "Embedded Generations". The DG as with a maximal load which is less than hundred (100) MW is defined by International Council on Large Electric System (IECLES), they are neither centrally organized nor dispatched they are connected with distribution network [1]. Now a days, there are four types of DGs are present in the market and some are still in development stage, and some are under research stage. Presently some available technologies are combustion gas turbine, wind turbine, microturbine, fuel cells etc. Everyone has its own limitations and benefits [2] [3].

Type I: Type I DG provides only real power in the system. PV cells and fuel cells are the best example of type-1 DG.

Type II: This type of DG efficient in capable of delivering only reactive power in the system to boost the system's voltage profile, e.g., capacitors, kvar compensators, synchronous compensators, etc.

Type III: This type of DG delivers both the active and the reactive power e.g., synchronous machine.

Type IV: This type of DG suitable for consuming reactive power and injecting actual energy example of this type of DG is induction generators work in wind farm.

In order to optimize DG positioning, most of the strategy described so far is considered only for Type-I DG only. In this paper, the optimal placement of the Type-III, Type II \& Type I is considered. PSO algorithm has solved the problem of optimal placement of DG by using exact loss formula as objective function. The particle swarm optimization methodology that is established on swarm intelligence technique is an optimization algorithm or heuristic global optimization method. It arises on the research of the behavior of fish-flock movement and bird. This algorithm has been most often used and quickly evolved for application compared to other heuristic methods. There is no mutation calculation \& overlap in the PSO technique. Development and research on several generations, study pace is very quick only the most optimistic particle can pass data to the other particles. There are many limitations such as power flow, present limit, voltage limit and the right-of-way to perform optimization. The suggested method was used to test 33-bus systems. Based on optimal place, ideal size \& loss minimization, the findings from PSO and analytical approach methods were co- 
related.

\section{Embedded Generation}

Cold loads pick up (CLPU) has been used by the authors in Ref. [4] to enhance the voltage regulation for the DGs' optimal placement. In order to find the best location and size of distribution generation genetic algorithm (GA) technique has been applied in reference [5].The local search ability is improved by the introduction of mutation operator. This also reduces the computation time and also reduces the distribution system losses [6]. PSO based technique is used to decrease the real power loss in the distribution system network author determine the optimal placement of DGs and capacitor In Ref. [7]. To decrease energy losses to the loads which is varying with the time the author placed capacitor and DGs together in radial distribution network in Ref [8]. In [9] for the optimal position of multiple DGs sources an enhanced reinitialized social structure PSO algorithm developed to reduce the real power loss, voltage, and power generation. The author uses ant colony search technique to reduce the losses in the system in Ref [10]. The optimum position of the DGs in [11] was determined for evenly growing load and evenly distributed load. To enhance the voltage profile and to decrease the active power losses and to determine the optimal placement of DG's analytical approach has been used in [12] [13] [14]. A swift analytical method is introduced to find the optimal size of distributed generation at optimal power. Size of distribution generation is found with the help of heuristic curve fitting process whereas sensitivity test is used to find the optimal location of the DGs [15] [16]. The optimal placement of capacitor to decrease the active power loss $2 / 3$ rule has been given in Ref. [17]. To reduce the cost of capacitor bank \& active power loss genetic algorithm has been presented in Ref. [18]. Size of capacitor and number of capacitor \& voltage limit has been resolved by considering various constraints. Heuristic technique, hybrid approach based search has been used in the reference [19] for capacitor placement. To determine sites of DGs and capacitor combinations and optimal size author used artificial bee colony algorithm in the reference [20]. Two load scenarios were worked out at predetermined power factor. The author used PSO method in the reference to determine the appropriate positioning of the condensers and to maximize the savings [21].

To get optimal size and position of DG's exact loss formula has been used by analytical approach in the reference [22]. Only type 3 distributed generations was considered in the work because analytical approach has been used by the author to get the optimal size of the DG's at optimal power factor.

\section{Loss Minimization in DG System}

Minimum losses occur in the distribution network because of the optimal size \& location of the DG. By applying the exact loss formula real power loss is reduce with the help of PSO. Loss minimize formula can be given by assuming $N$ bus distribution system network. 


$$
\text { Minimize } P_{L}=\sum_{i=1}^{N} \sum_{j=1}^{N}\left[\alpha_{i j}\left(P_{i} P_{j}+Q_{i} Q_{j}\right)+\beta_{i j}\left(Q_{i} P_{j}-P_{i} Q_{j}\right)\right]
$$

where

$$
\begin{gathered}
\alpha_{i j}=\frac{r_{i j}}{V_{i} V_{j}} \cos \left(\delta_{i}-\delta_{j}\right) \\
\beta_{i j}=\frac{r_{i j}}{V_{i} V_{j}} \sin \left(\delta_{i}-\delta_{j}\right)
\end{gathered}
$$

and

$$
Z_{i j}=r_{i j}+j x_{i j}
$$

It must be satisfied with I system energy flow equations.

$$
\begin{gathered}
P_{G i}-P_{D i}=\sum_{j=i}^{N} V_{i} V_{j}\left[G_{i j} \cos \left(\delta_{i}-\delta_{j}\right)+B_{i j} \sin \left(\delta_{i}-\delta_{j}\right)\right] \\
Q_{G i}-Q_{D i}=\sum_{j=i}^{N} V_{i} V_{j}\left[G_{i j} \sin \left(\delta_{i}-\delta_{j}\right)-B_{i j} \cos \left(\delta_{i}-\delta_{j}\right)\right]
\end{gathered}
$$

For $i=1,2,3, \cdots, N$

$B_{i j}$ is the susceptance of the line between the bus $i$ and bus $j$ and $G_{i j}$ is the conductance of the line bus $i$ and bus $j$

$$
P_{i}=P_{G i}-P_{D i} \text { and } Q_{i}=Q_{G i}-Q_{D i}
$$

$Q_{G i}$ and $P_{G i}$ are generators in bus $i$ power generation. $Q_{D i}$ and $P_{D i}$ are loads on thebus $i$.

Voltage constraints must be met for each bus $( \pm 5 \%$ of the rated voltage) should be fulfilled [23].

$$
V_{\min } \leq V_{i} \leq V_{\max } \text { where } i=1,2,3, \cdots, N
$$

The constraint limiting the current through the line is given by.

$$
I_{i} \leq I_{i}^{\text {Rated }} \text { for all } i \text { branches of the network\} }
$$

where $I_{i}^{\text {Rated }}$ is currently permitted for the branch $i$ within a secure temperature threshold.

Right-of-way buses (busses that are not suitable for DG distribution because of certain restrictive factors) are not included.

\subsection{Computational Technique}

Particle swarm optimization technique was applied to derive the ideal place and size of distinct kinds of DGs. In the scheme the required objective forward sweep and backward sweep technique of distributed load flow was used. The following chapter summarizes the information of the analytical strategy and PSO.

\subsection{Particle Swarm Optimization Technique}

PSO approach based technique is a population-based search procedure based on the optimization technique of the population. Particles can fly around in a mul- 
tidimensional (n-dimensional) search space with respect to time in particle swarm optimization technique. Every particle adapts its place based on its own knowledge (this is called pbest) \& it is called gbest based on the neighboring particle by comparing the best place with its neighboring particle.

Mathematically, in an $\mathrm{n}$-dimensional vector the position of vector is given as:

$$
X_{m}=\left(x_{m, 1}, x_{m, 2}, x_{m, 3}, \cdots, x_{m, n}\right)
$$

The present position is changed by the following equation:

$$
S_{i d}^{k+1}=S_{i d}^{k}+v_{i d}^{k+1}, i=1,2, \cdots, n ; d=1,2, \cdots, m
$$

where $S^{k}$ is the particle's present position and $S^{k+1}$ is the particle's changed position

Every particle's velocity can be modified by this equation:

$$
\begin{gathered}
v_{i d}^{k+1}=\omega v_{i d}^{k}+c_{1} \text { rand } \times\left(\text { pbest }_{i d}-s_{i d}^{k}\right)+c_{2} \text { rand } \times\left(\text { gbest }_{i d}-s_{i d}^{k}\right) \\
\omega_{i}=\omega_{\max }-\frac{\omega_{\max }-\omega_{\min }}{k_{\max }} k
\end{gathered}
$$

where the maximum and minimum weights are $\omega_{\max }$ and $\omega_{\min }$. The actual iteration and the highest amount of iterations are $k$ and $k_{\max }$. Appropriate values are in the range $1-2$ for $c_{1}$ and $c_{2}$. For the PSO algorithm's rapid convergence, values of $c_{1}, c_{2}, \omega_{\min }$ and $\omega_{\max }$ chosen randomly [24] and the final values are regarded as: $c_{1}=c_{2}=2, \omega_{\min }=0.4$ and $\omega_{\max }=0.9$.

And among all the particle the global best position is given by:

$$
\begin{gathered}
\text { Pbest }_{m}=\left(\text { pbest }_{m, 1}, \text { pbest }_{m, 2}, \cdots, \text { pbest }_{m, n}\right) \\
\text { Gbest }_{m}=\left(\text { gbest }_{m, 1}, \text { gbest }_{m, 2}, \cdots, \text { gbest }_{m, n}\right)
\end{gathered}
$$

The position and the velocity of the particles up renew after each iteration. In the network value of distributed generation (DG) vary from zero to sum of the loads (continuous). The PSO algorithm specifies the number of iterations and particle swarm size. The $V_{m}$ and $X_{m}$ are the velocity and position of the $m$ th particle. PSO is a meta heuristic because it makes few or no hypotheses about the optimized problem and searches for other alternatives. Figure 1 shows the flow chart by applying PSO to optimize the sitting of various kinds of DGs.

\subsection{Analytical Approach}

By applying analytical approach method sites and sizes of various kinds of the DGs are also established. Exact loss formula is given in (1). If partial derivative of (1) with respect to injected power becomes [13].

$$
\frac{\partial P_{L}}{\partial P_{i}}=2 \alpha_{i i} P_{i}+2 \sum_{J=1, J \neq i}^{N}\left(\alpha_{i i} P_{j}-\beta_{i i} Q_{j}\right)=0
$$

It follows that

$$
P_{i}=-\frac{1}{\alpha_{i i}}\left[\sum_{J=1, J \neq i}^{N}\left(\alpha_{i i} P_{j}-\beta_{i i} Q_{j}\right)\right]
$$




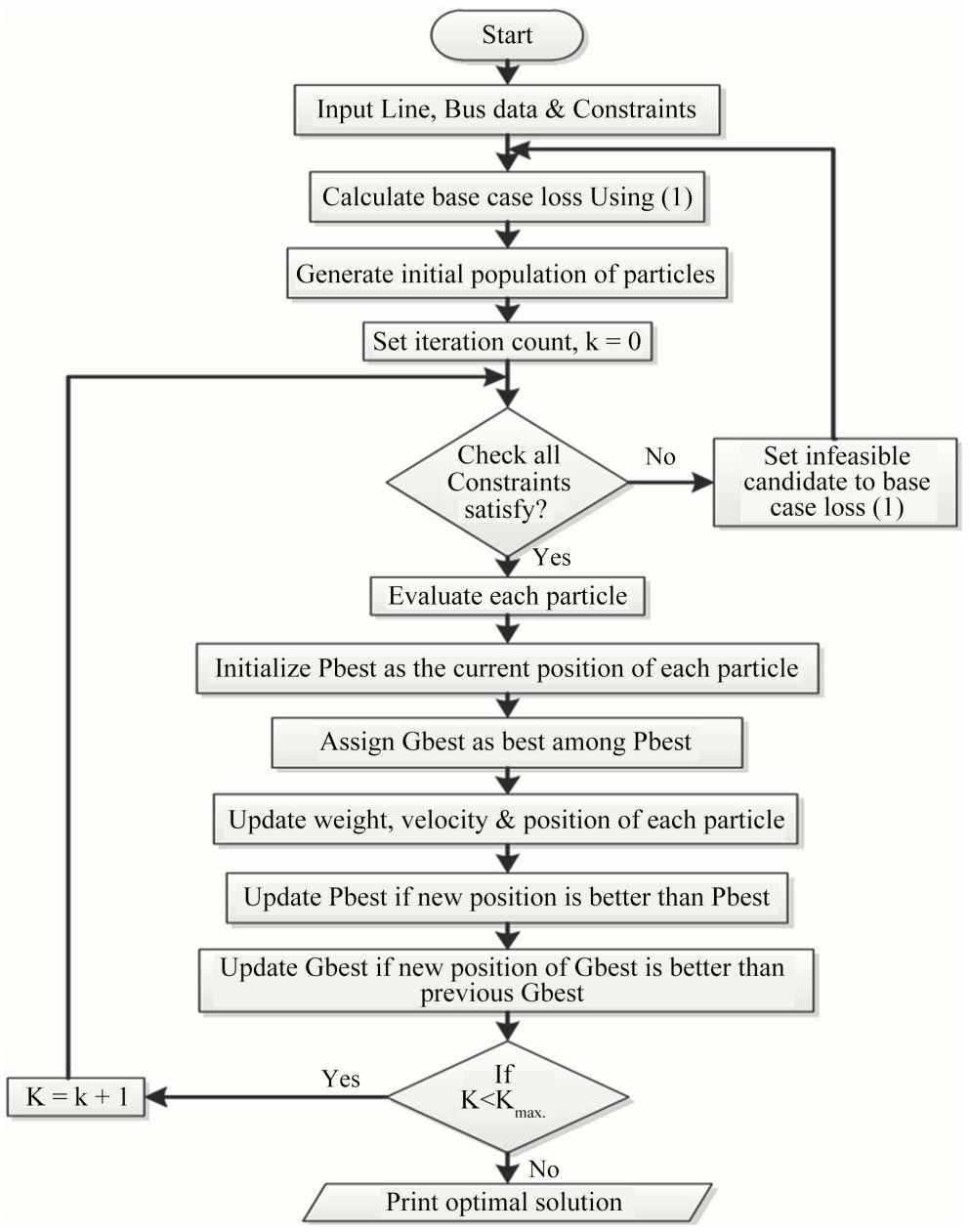

Figure 1. Flow chart of optimal placement of distribution generators using particle swarm optimization.

where $P_{i}$ can be given as:

$$
\begin{gathered}
P_{i}=\left(P_{D G i}-P_{D i}\right) \\
P_{D G i}=P_{D i}-\frac{1}{\alpha_{i i}}\left[\sum_{J=1, J \neq i}^{N}\left(\alpha_{i i} P_{j}-\beta_{i i} Q_{j}\right)\right]
\end{gathered}
$$

Similarly reactive power for

$$
\begin{gathered}
\frac{\partial P_{L}}{\partial Q_{i}}=2 \alpha_{i i} Q_{i}+2 \sum_{J=1, J \neq i}^{N}\left(\alpha_{i i} Q_{j}-\beta_{i i} P_{j}\right)=0 \\
Q_{i}=\left(Q_{D G i}-Q_{D i}\right)
\end{gathered}
$$

Therefore

$$
Q_{D G i}=Q_{D i}-\frac{1}{\alpha_{i i}}\left[\sum_{J=1, J \neq i}^{N}\left(\alpha_{i i} Q_{j}-\beta_{i i} P_{j}\right)\right]
$$

Equation (21) provides information on the size of Type-II DG and Equation (18) provides information on Type I DG on each bus [15]. When we compared with same type of DG, type-I DG placed at ith bus giving the least active power 
loss then th bus becomes the best for placement of type-I DG.

Any DG size other than $P_{P D i}$ and $Q_{D G i}$ positioned on the bus, it may result in greater losses. For the Type III DG's the optimum power factor is shown as:

$$
\mathrm{OPF}=\frac{P_{D G i}}{\sqrt{P_{D G i}^{2}+Q_{D G i}^{2}}}
$$

The Equation (22) can depict Type-III DG's power factor. In this work to generate active and reactive power type-III DG is used. The DG with reactive power absorbing capacity would require the leading power factor load.

To satisfy system limitations, the bus with the smallest energy loss can be regarded as the optimum place for DG's positioning. The computing method is outlined below to calculate the optimal site, size, and power factor of DGs.

Step (1): Run the load flow for base case without making use of distribution generators.

Step (2): Find out the base case losses by using Equation (1).

Step (3): Except for the reference bus, by using Equations (18) \& (21) for minimum distribution loss find out the size of different type of DGs.

Step (4): Violation of the DG check constraint set out in the step (3) for every bus after positioning.

Step (5): satisfying all the constraint for optimal placement then select the bus for less losses.

Step (6): Using Equation (22) evaluate the power factor for type-III DG.

Step (7): Execute the flow of load at the optimal bus with the optimal size of DG.

Step (8): Evaluate the decrease in the active power loss after DG positioning.

\section{System Modelling}

\subsection{Test Systems}

The initial scheme with 33-bus radial distribution systems and the complete system load is 3.72 MW and 2.3 Mvar in equation [25]. Two separate kinds of test devices have evaluated for the analytical method and the PSO approach suggested in the paper. The 69-bus radial distribution system is the second radial distribution system with a total connected load of 3.80 MW and 2.69 Mvar [26]. The optimization technique has been solved in MATLAB.

\subsection{Site and Size Allocation of the Distribution Generators Using the Particle Swarm Optimization}

In this research, the following two cases are considered. The first case analyzes the appropriate positioning of each DG type i.e., the type-III/type-II/type-I DGs are put in the scheme independently where we are calculating the power loss comparison.

Between different kinds of DG's i.e., type-1, type-2, type- 3 before and after the DG's placement and in second case we are calculate the voltage profile before 
and after the DG's placement. After that we are compare both the DG's before and after the DG's placement.

PSO approach based technique has been proposed for the 33 bus system for the optimal placement of each distribution generators type. For optimization, the particle swarm optimization parameters are chosen as: $\mathrm{c} 1=\mathrm{c} 2=2$, total number of iterations $=80$, swarm size $=50$.

The optimal position \& size are obtained in different cases and percentage saving is given below in table number 1.

It is acknowledged that no single type-II distributed generation has been discovered by the algorithm, that satisfying every system limitation.

However, a type-II distributed generation with the optimal size of 1.27 Mvar positioned at bus number 18 minimize the losses up to $146.84 \mathrm{KW}$ and increase the voltage profile from 0.91309 to 0.92954 .

For the positioning of Type-III DG, the optimal bus location for the 33 bus system is calculated to be 18 . The power factor and the size of type-III DG on these buses is calculated and displayed in Table using the PSO algorithm. For the 33 bus system, the reduction in active power losses is $38.69 \%$. Figures $1-3$ indicate voltage in per unit of distinct DG kinds for 33 on bus.

The complete power loss for various kinds of distribution generators is shown in Figures 4-6 for reducing the actual power

From the outcomes, it is noted that the losses are greater when large-size DGs are positioned close the reference bus. By comparison, a greater loss decrease can be accomplished if tiny size DGs is positioned at farther places.

\subsection{Analytical Approach for Determining the Site Allocation and Size of Each Type of Distribution Generators}

To obtain the optimal place and size of the DGs, the analytical approach described in this section has been implemented. Similar outcomes are obtained for the type-I and type-II distribution generators for analytical approach as we obtained in the particle swarm optimization strategy as shown in Table 1 and Table 2.

The findings show that when Type-I and Type-II DGs are positioned on separate ideal buses, the actual power losses of the scheme are reduced. Before the DG placement of the type-I DG voltage per unit is about to 0.91309 p.u. voltage and after the DG placement voltage per unit is 0.9937 p.u so the percentage change in the voltage is $8.8 \%$ p.u and similarly for the second type-II of the distributed generation before the distributed generator placement voltage per unit at the bus number 18 before the DG placement minimum voltage in p.u is 0.91410 and after the DG placement voltage in per unit is 0.9987 so the percentage increase in the $9.25 \%$ p.u and for the Type-III distributed generator per unit voltage before the DG is placement is 0.91645 and after the DG placement the voltage p.u is 1.001 so the percentage increase in the voltage after the distribute generation is $9.22 \%$ in p.u. 


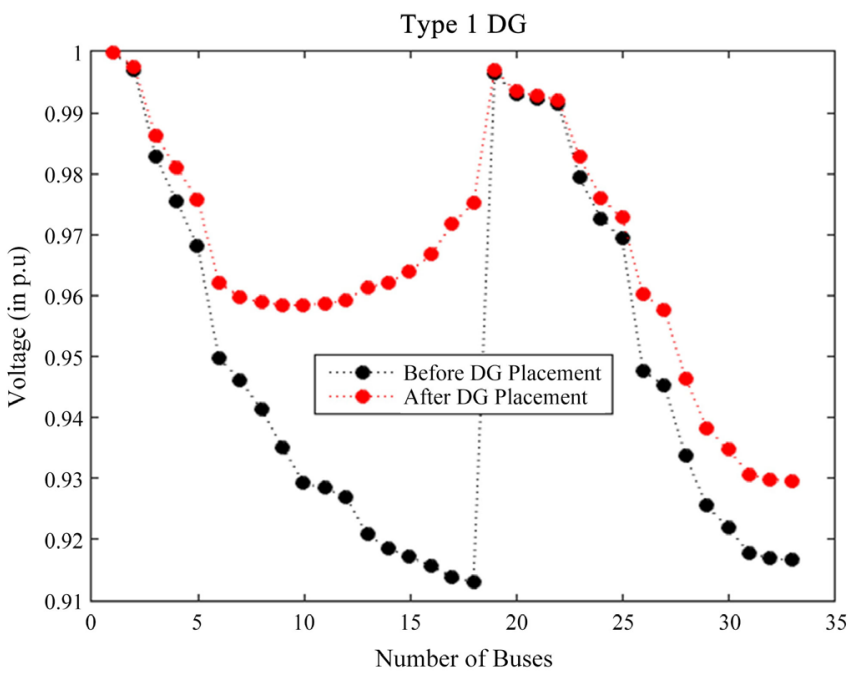

Figure 2. Comparison of P.U voltage before and after DG (type 1) placement.

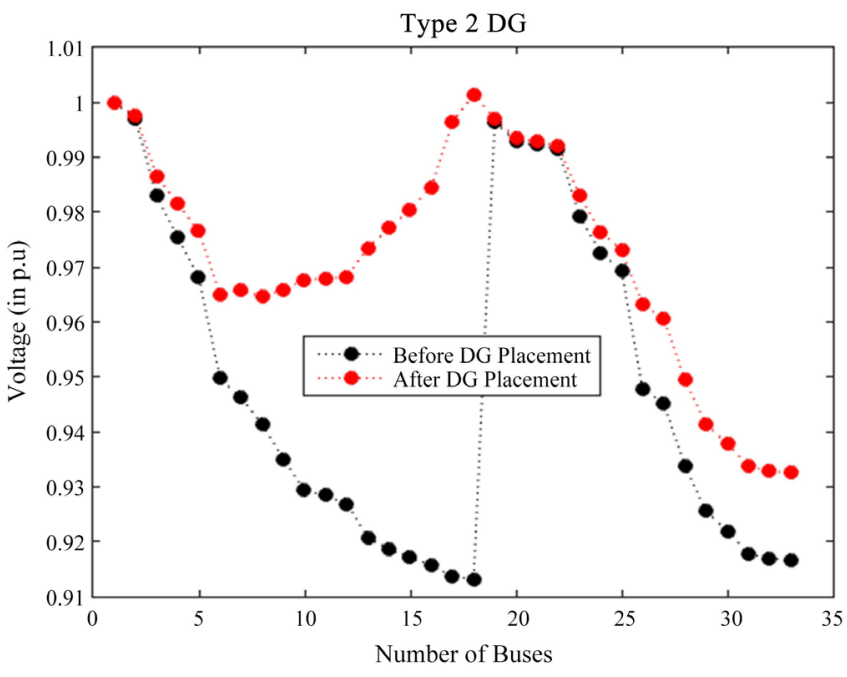

Figure 3. Comparison of P.U voltage before and after DG (type 2) placement.

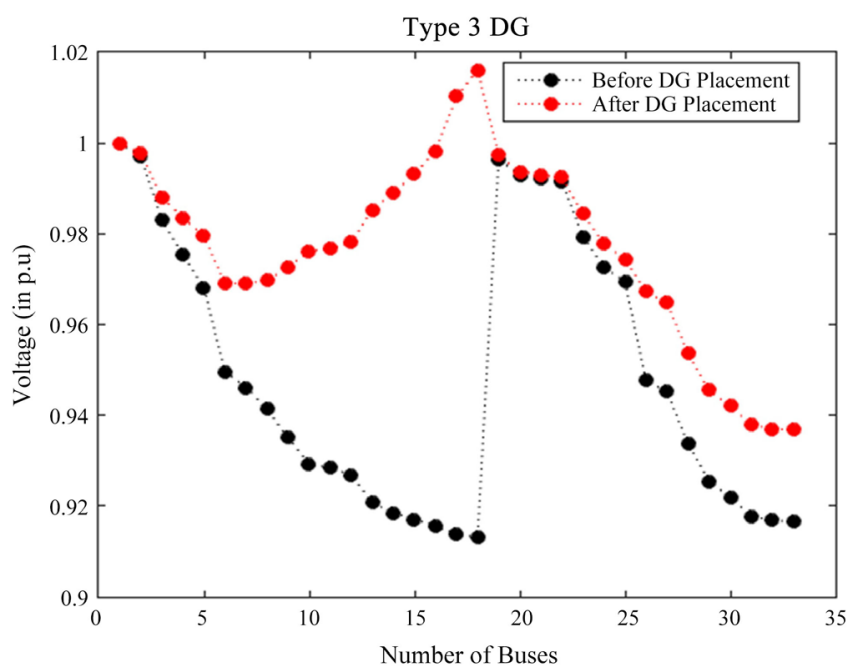

Figure 4. Comparison of P.U voltage before and after DG (type 3) placement. 


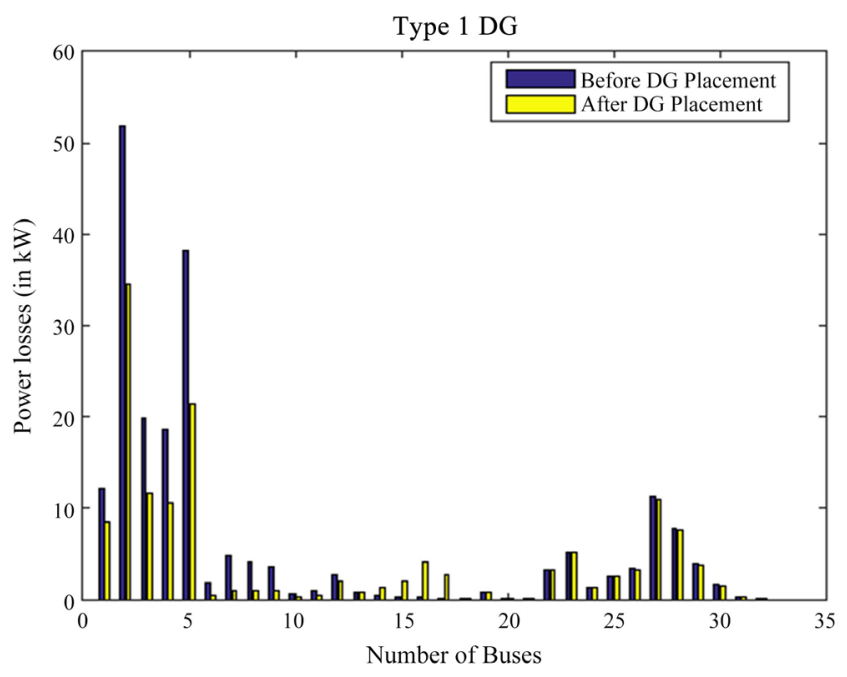

Figure 5. Total power loss of 33 bus distributions system in type 1 DG system.

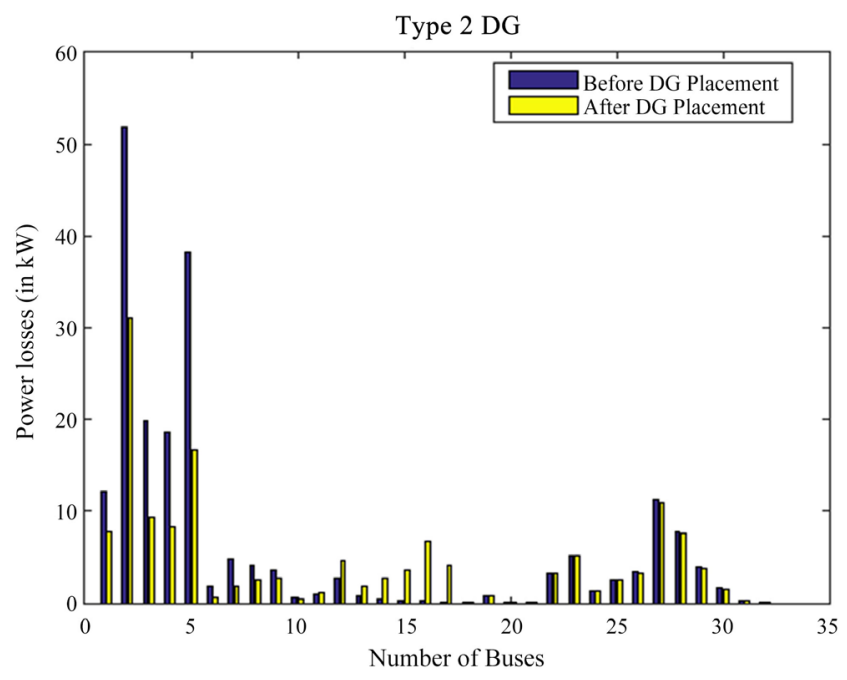

Figure 6. Total power loss of 33 bus distributions system in type 2 DG system.

Table 1. Optimal size of different types of DGs.

\begin{tabular}{rcccccc}
\hline \multirow{2}{*}{ System } & DG type & Bus No. & DG size in $(\mathrm{KW})$ & \multicolumn{2}{c}{ Optimal size of different type of DG } \\
\hline 33 bus & Type 1 & 18 & 850.5436 & 3.10 & MVar & MVA, pu \\
33 bus & Type 2 & 18 & 486.6003 & & 1.27 & $3.02,082$ leading \\
\hline 3 bus & Type 3 & 18 & 984.8795 & & & \\
\hline
\end{tabular}

Table 2. Results of different types of systems before and after DG placement.

\begin{tabular}{|c|c|c|c|c|c|c|c|c|c|c|}
\hline \multirow[b]{2}{*}{ System } & \multirow[b]{2}{*}{$\begin{array}{l}\text { DG } \\
\text { type }\end{array}$} & \multirow{2}{*}{$\begin{array}{l}\text { Bus } \\
\text { No. }\end{array}$} & \multirow{2}{*}{$\begin{array}{l}\text { DG size } \\
\text { in }(K W)\end{array}$} & \multicolumn{2}{|c|}{ Before DG placement } & \multicolumn{3}{|c|}{ After DG placement } & \multicolumn{2}{|c|}{ Percentage saving } \\
\hline & & & & Ploss (KW) & $\begin{array}{c}\text { Minimum } \\
\text { Voltage (p.u.) }\end{array}$ & Ploss (KW) & $\begin{array}{c}\text { Minimum } \\
\text { Voltage (p.u.) }\end{array}$ & $\begin{array}{c}\text { Reactive } \\
\text { power (kVAr) }\end{array}$ & $\begin{array}{l}\text { Power } \\
\text { saving }\end{array}$ & $\begin{array}{l}\text { Voltage } \\
\text { saving }\end{array}$ \\
\hline 33 bus & Type 1 & 18 & 850.5436 & 202.6771 & 0.91309 & 144.2316 & 0.9937 & & 28.83 & 8.82 \\
\hline 33 bus & Type 2 & 18 & 486.6003 & 202.6771 & 0.91410 & 146.814 & 0.9987 & & 27.56 & 9.25 \\
\hline 33 bus & Type 3 & 18 & 984.8795 & 202.6771 & 0.91645 & 124.2559 & 1.001 & 566.0156 & 38.69 & 9.22 \\
\hline
\end{tabular}


The optimum size of the 33-bus scheme of type-III DG is acquired by particle swarm optimization method and by analytical strategy. The actual energy loss achieved by both methods is also slightly distinct due to the difference in the power factor and size.

In analytical approach, to determine the optimal location, it consumes much more time for large systems to evaluate the size of Type-I and Type-II on every bus. So, this approach is not appropriate for putting different distribution generator as the next distribution generator magnitude may not be optimal to minimize losses. Therefore, heuristic techniques are more suitable for finding the optimum location and size of different distribution generators in a larger system.

The lowest and peak voltages for Type-I, Type-II and Type-III test systems are shown in Tables. From these outcomes it is noted that the voltage profile considerably increases in all instances after ideal positioning of each type of distribution generators.

\section{Simulation Results and Discussion}

This research described the optimal allocation of distinct kinds of distribution generators using the reactive power and the active power compensation particle swarm optimization method to minimize the actual losses of power in main distribution networks. In order to minimize the energy loss, the appropriate power factor was also determined. The analytical strategy evaluates each system bus to discover the optimal solution so we can say that analytical approach is used for smaller system to get the optimal size and location in a system. However, heuristic methods are more appropriate in a bigger system because searches converge quickly into a solution. The suggested PSO strategy to optimally place various kinds of DGs decreases line losses as well as minimizes distribution generator sizes to satisfy the permissible voltage boundaries. The positioning and evaluation of various kinds of DGs in the era of embedded grid provide guidance for ideal energy system operation.

\subsection{Comparison of Voltage (in p.u) before and after the Placement for All Type of DGs}

It is observed that in Figure 1 for the bus number 18 before the distribution placement (type1) voltage p.u lie between 0.91 to 0.92 and after the DG placement voltage per unit almost equivalent to 1 p.u. The voltage in the system is increase after the DG placement. So, foe the optimal placement of the type $1 \mathrm{DG}$ it is found to be placed at bus number 18 .

Figure 3 shows the comparison between voltage (in p.u) and the number of buses before the distribution generation placement and after the DG placement. It is observed that at bus number 18 in the figure shown above that before DG placement at bus 18 voltage p.u is equivalent to 0.91 and after the DG placement of type 2 voltage p.u is equal to 1 .

So, in Figure 4 comparison between the voltage per unit at the bus number 18 
before and after the distribution generation placement. It is clearly observed that after the distribution placement of type 3 voltage per unit is increased at bus number 18 for the type of $33 \mathrm{kv}$ bus system. In Figure 3, black dots represent before the DG placement and the red dots represent after the DG placement. We have observed that before the DG placement voltage p.u is nearly equal to 0.92 p.u and after the DG placement voltage per unit is equal to $1.01 \mathrm{p}$. $\mathrm{u}$ which is almost equal to 1 p.u.

\subsection{Power Loss Comparison for All Types of DG before and after DG Placement}

For the type-I DG placement, bus number 2 and 5 are found to be the optimal buses for the 33 bus system. For the system after the DG placement total loss in the system is decrease.

It is observed that in figure number 6, comparison between power losses and the different number of buses. We observed that after the DG placement at each bus total power loss in the system is decreased.

Figure 7 shows comparison between the system's total power loss before and after the DG placement. Type-III DG can inject both active and reactive power in the system so total power loss at each bus after the DG placement of Type-III is decrease.

\subsection{Summary of the Results}

Brief study of results before and after DG placement, calculation of p.u. power losses is as follows (Table 1).

Particle swarm optimization technique has been used to get the optimal size and location of the 33 bus system. By using the PSO algorithm we get the optimal bus is 18 for each type of DG'S.

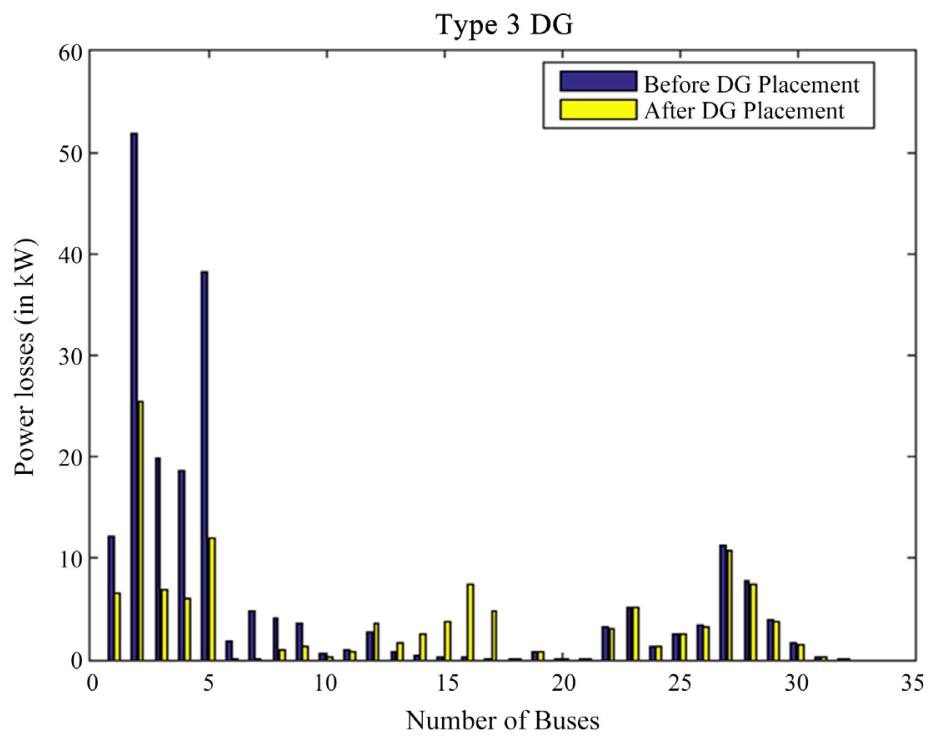

Figure 7. Total power loss of 33 bus distributions system in type 3 DG system. 
In Table 2, we have compared the results of different types of DG's before and after the DG's placement. By the help of above results we have found that losses in power (KW) \& voltage (p.u) are decreased. For typel DG after the DG placement at optimal bus 18 power losses and voltage saving is $28.83 \%$ \& $8.82 \%$. For the type2 DG percentage of power and voltage saving is $27.56 \& 9.25$ similarly for the type 3 bus the power saving and voltage saving is $38.68 \%$ and $9.22 \%$.

\section{Conclusions}

This paper uses practical and adaptive energy compensation PSO techniques with the help of various kinds of DGs to reduce primary distribution network's actual power losses. In order to mitigate the power losses, the optimal power factor is also calculated at the same time. The PSO based technique has also been contrasted with the analytical approaches. Therefore, it is best to find the size of the distribution generations in the minor systems, because each bus system is analyzed by the analytical method to try the optimal solution. Nonetheless, in large systems, the heuristic approaches are much reasonable as the searches rapidly converge into a solution. The proposed PSO approach based solution minimizes the line losses and at the same time minimizes the sizes of distribution generations to reach the appropriate voltage limits apart from optimally allocating multiple types of DGs. The analysis and placement of the various kinds of DGs in the integrated grid age provide instructions for optimum operation of the power system.

In future, we can work on the all types of the buses placed simultaneously to show the maximum and minimum voltages for the buses. In addition to that work on simultaneous placement of Type-I and Type-II for the 33 bus system could be done. In the present work, results obtained from the individual allocation of all kinds of buses.

\section{Conflicts of Interest}

The authors declare no conflicts of interest regarding the publication of this paper.

\section{References}

[1] CIGRE (2018) Impact of Increasing Contribution of Dispersed Generation on the Power System. Working Group 37.23.

[2] EL-Khattam, W. and Salama, M.M.A. (2018) Distributed System Planning Using Distributed Generation. Proceeding of IEEE Canadian Conference on Electrical and Computer Engineering, Vol. 1, 579-582.

[3] Akhtar, I., Paul, W.U.H., Kirmani, S. and Asim, M. (2021) Cost Analysis of 18 kW Solar Photovoltaic System for Smart Cities Growth in India. In: Iqbal, A., Malik, H., Riyaz, A., Abdellah, K. and Bayhan, S., Eds., Renewable Power for Sustainable Growth, Lecture Notes in Electrical Engineering, Vol. 723, Springer, Singapore, 661-667. https://doi.org/10.1007/978-981-33-4080-0 63

[4] Kumar, V., Kumar, R., Gupta, I. and Gupta, H.O. (2017) DG Integrated Approach 
for Service Restoration under Cold Load Pickup. IEEE Transactions on Power Delivery, 25, 398-406. https://doi.org/10.1109/TPWRD.2009.2033969

[5] Kim, J.O., Nam, S.W., Park, S.K. and Singh, C. (2013) Dispersed Generation Planning Using Improved Hereford Ranch Algorithm. Electric Power Systems Research, 47, 47-55. https://doi.org/10.1016/S0378-7796(98)00038-8

[6] Zhang, D., Fu, Z. and Zhang, L. (2007) An Improved TS Algorithm for Loss Minimum Reconfiguration in Large-Scale Distribution Systems. Electric Power Systems Research, 77, 685-694. https://doi.org/10.1016/j.epsr.2006.06.005

[7] Kansal, S., Kumar, V. and Taygi, B. (2012) Composite Active and Reactive Power Compensation of Distribution Networks. 7 th IEEE International Conference on Industrial and Information Systems, Chennai, 6-9 August 2012, 1-6. https://doi.org/10.1109/ICIInfS.2012.6304764

[8] Sajjadi, S.M., Haghifam, M.R. and Salehi, J. (2013) Simultaneous Placement of Distributed Generation and Capacitors in Distribution Networks Considering Voltage Stability Index. International Journal of Electrical Power \& Energy Systems, 46, 366-375. https://doi.org/10.1016/j.ijepes.2012.10.027

[9] Prommee, W. and Ongsakul, W. (2011) Optimal Multiple Distributed Generation Placement in Microgrid System by Improved Reinitialized Social Structures Particle Swarm Optimization. European Transactions on Electrical Power, 21, 489. https://doi.org/10.1002/etep.456

[10] Su, C.T., Chang, C.F. and Chiou, J.P. (2005) Distribution Network Reconfiguration for Loss Reduction by Ant Colony Search Algorithm. Electric Power Systems Research, 75, 190-199. https://doi.org/10.1016/j.epsr.2005.03.002

[11] Griffin, Tomsovic, K., Secrest, D. and Law, A. (2000) Placement of Dispersed Generation Systems for Reduced Losses. Proceedings of 33rd Annual Hawaii International Conference on System Sciences, Maui, 4-7 January 2000, 1-9.

[12] Wang, C. and Nehrir, M.H. (2004) Analytical Approaches for Optimal Placement of DG Sources in Power Systems. IEEE Transactions on Power Systems, 4, 2068-2076. https://doi.org/10.1109/TPWRS.2004.836189

[13] Acharya, N., Mahat, P. and Mithulananthan, N. (2006) An Analytical Approach for DG Allocation in Primary Distribution Network. International Journal of Electrical Power \& Energy Systems, 28, 669-678. https://doi.org/10.1016/j.ijepes.2006.02.013

[14] Gozel, T. and Hocaoglu, M.H. (2009) An Analytical Method for the Sizing and Sitting of Distributed Generators in Radial Systems. Electric Power Systems Research, 79, 912-918. https://doi.org/10.1016/j.epsr.2008.12.007

[15] Paul, W.U.H., Bhat, M.B., Kirmani, S. and Nahvi, S.A. (2020) Data Based Controller Design for PMDC Motor Setup Using System Identification. Studies in Indian Place Names, 40, 11.

[16] Hung, D.Q., Mithulananthan, N. and Bansal, R.C. (2010) Analytical Expressions for DG Allocation in Primary Distribution Networks. The IEEE Transactions on Energy Conversion, 25, 814-820. https://doi.org/10.1109/TEC.2010.2044414

[17] Abu-Mouti, F.S. and El-Hawary, M.E. (2011) Heuristic Curve-Fitted Technique for Distributed Generation Optimization in Radial Distribution Feeder Systems. IET Generation, Transmission \& Distribution, 5, 172-180. https://doi.org/10.1049/iet-gtd.2009.0739

[18] Schmill, J.V. (1965) Optimum Size and Location of Shunt Capacitors on Distribution Feeders. IEEE Transactions on Power Apparatus and Systems, 84, 825-832. https://doi.org/10.1109/TPAS.1965.4766262 
[19] Masoum, M.A.S., Ladjevardi, M., Jafarian, A. and Fuchs, E.F. (2004) Optimal Placement, Replacement, and Sizing of Capacitor Banks in Distorted Distribution Networks by Genetic Algorithms. IEEE Transactions on Power Delivery, 19, 1794-1801. https://doi.org/10.1109/TPWRD.2004.835438

[20] Gallego, R.A., Monticelli, A.J. and Romero, R. (2001) Optimal Capacitor Placement in Radial Distribution Networks. IEEE Transactions on Power Delivery, 16, 630-637. https://doi.org/10.1109/59.962407

[21] Abu-Mouti, F.S. and El-Hawary, M.E. (2011) Optimal Distributed Generation Allocation and Sizing in Distribution Systems via Artificial Bee Colony Algorithm. IEEE Transactions on Power Delivery, 26, 2090-2101.

https://doi.org/10.1109/TPWRD.2011.2158246

[22] Singh, S.P. and Rao, A.R. (2012) Optimal Allocation of Capacitors in Distribution Systems Using Particle Swarm Optimization. International Journal of Electrical Power \& Energy Systems, 43, 1267-1275.

https://doi.org/10.1016/j.ijepes.2012.06.059

[23] Elgerd, I.O. (1971) Electric Energy System Theory-An Introduction. McGraw-Hill, New York.

[24] Eberhart, R.C. and Shi, Y. (2000) Comparing Inertial Weights and Constriction Factor in Particle Swarm Optimization. Proceedings of the 2000 Congress on Evolutionary Computation. CECOO (Cat. No.00TH8512), 1, 84-88.

[25] Kashem, M.A., Ganapathy, V., Jasmon, G.B. and Buhari, M.I. (2000) A Novel Method for Loss Minimization in Distribution Networks. Proceedings of International Conference on Electric Utility Deregulation and Restructuring and Power Technology, London, 4-7 April 2000, 251-256.

[26] Baran, M.E. and Wu, F.F. (1989) Optimal Capacitor Placement on Radial Distribution Systems. IEEE Transactions on Power Delivery, 4, 725-734.

https://doi.org/10.1109/61.19265 